\title{
THE EFFECT OF SUPERSATURATION CONTROL STRATEGY FOR PHOSPHATE RECOVERY THROUGH PRECIPITATION OF STRUVITE IN AN AIR-AGITATED COLUMN REACTOR
}

\author{
L. Edahwati' , S. Sutiyono ${ }^{1}$, S. Muryanto ${ }^{2}$, J. Jamari ${ }^{3}$ and A. P. Bayuseno ${ }^{3, *}$ \\ ${ }^{1}$ Department of Chemical Engineering, Universitas Pembangunan National "Veteran" Jawa \\ Timur, Indonesia \\ ${ }^{2}$ Department of Chemical Engineering, UNTAG University in Semarang, Bendhan Dhuwur \\ Campus, Semarang, Indonesia \\ ${ }^{3}$ Department of Mechanical Engineering, Diponegoro University, Tembalang Campus, \\ Semarang, Indonesia \\ *E-mail: apbayuseno@gmail.com
}

\begin{abstract}
MAP (magnesium ammonium phosphate) precipitation through supersaturation restriction strategy for phosphorus recovery from an aqueous solution is presented in the study. The air-agitated column reactor was designed with three feed ports for the MAP solution entry, while the levels of the supersaturated solution at varying $\mathrm{pH}(8,9$ and 10) were examined at the different retention time. At $\mathrm{pH} \mathrm{10,} \mathrm{the} \mathrm{recovery} \mathrm{phosphorus} \mathrm{efficiency} \mathrm{decreased} \mathrm{with} \mathrm{an}$ increase in the retention time, but increased gradually with an increase in the retention time under $\mathrm{pH} 10$. Meanwhile, X-ray powder diffraction (XRPD) method proved that the high purity of struvite could be produced, while its morphology observed by scanning electron micrograph (SEM) was irregular prismatic with diverse crystal size. Obviously, the supersaturation restriction strategy may be applied for the increased phosphorus recovery efficiency through struvite formation in the reactor observed during the work.
\end{abstract}

Keywords: Phosphorus retrieval, Supersaturation restriction, Struvite, MAP precipitation, varying $\mathrm{pH}$

@ RASĀYAN. All rights reserved

\section{INTRODUCTION}

The high concentration of phosphate in wastewater may cause eutrophication of surface waters. This great issues raised by the environmental engineer are being addressed through the development of recovery strategies of nutrient from liquid wastes in more sustainable systems ${ }^{1}$. The sustainable approach has been widely implemented for MAP precipitation in advanced biological nutrient removal (BNR) plants through the evolution of many reactor systems. Furthermore, the induced MAP crystallization in the formation of struvite for phosphorus recovery from wastewater is an economical and efficient approach, which in turn yields an effective phosphorus recovery and high-quality crystallization products ${ }^{2-4}$. Now, several kinds of reactors have been developed into a research lab, pilot, and full-scale and have demonstrated the outstanding potential for the formation of struvite for recovering phosphate ${ }^{5,6}$. However, the extent of struvite and its crystallite size formed within the reactor have brought much concern. This is because the struvite fines can grow and easily flush out of the reactor and hence be influencing phosphate recovery efficiency. Moreover, the discharge of particles from the reactor to liquid/solids filtrating equipment result in precipitation and scaling in downstream conduits. Therefore, a reactor should be designed with the separation devices, which can promote crystallized products with optimum settling characteristics and control powder particle morphology.

Additionally, the designed and tested lab-scale of a reactor for struvite crystallization is frequently incorporated by the precipitate in a special compartment for liquid/solid separation. Here the reactor is usually equipped with seed materials (e.g. quartz and periclase grains), of which their surfaces may assist 
as nucleation sites for struvite precipitation ${ }^{7}$. Ferric chloride and aluminum sulfate can also be used for coagulants to agglomerate struvite fines into large particles ${ }^{8}$.

On the other hand, the physicochemical parameters in the reactor may influence the quality of struvite. In this case, fully controlled conditions and partly purifying wastewater systems are required in the reactor system $^{5}$. Moreover, struvite crystals with prismatic or needle-like, homogeneous in size and possibly large are preferable for practical use as mineral fertilizer in agriculture ${ }^{9,10}$. Additionally, a number of impurities, which can be co-precipitated from the wastewater, should be restricted ${ }^{11}$. For example, the presence of high concentration $\mathrm{Ca}^{2+}$ in the solution may decrease the percentage of $\mathrm{Mg}^{2+}$ and $\mathrm{NH}^{4+}$ to be recovered. In general, the organic matter present in the solution makes a decrease in the size of struvite crystals, while the need for reagents to adjust the $\mathrm{pH}$ may reduce for the $\mathrm{CO}_{2}$ stripping.

The further quality of struvite may be controlled by the supersaturated solutions in the reactor, which can be manipulated by the different $\mathrm{pH}$ and multiple reagents feed points for the MAP precipitation of orthophosphate recovery ${ }^{12,13}$. Role of three metal salts $\left(\mathrm{AlCl}_{3}, \mathrm{CaCl}_{2}\right.$, and $\left.\mathrm{MgCl}_{2}\right)$ on orthophosphate recovery provided the preference order by placing $\mathrm{MgCl}_{2}, \mathrm{CaCl}_{2}$, and $\mathrm{AlCl}_{3}$ respectively, when it is added into the solution providing the $\mathrm{pH}$ range of $7-10^{13}$. Moreover, the use of $\mathrm{MgCl}_{2}$ addition to phosphate precipitation yield in particles with better settleability compared with the results of using $\mathrm{AlCl}_{3}$ and $\mathrm{CaCl}_{2}$. Correspondingly, the phosphate recovery efficiency could be improved using a low-cost $\mathrm{MgO}$ combined with air stripping with a recirculation stream inside the reactor. Meanwhile, the MAP crystallization occurs preferably in the alkaline condition and completely mixed state. Prediction of potential for struvite precipitation (at the level of $140 \mathrm{mg} / \mathrm{l}$ ) may be achieved at about $\mathrm{pH}$ of $7.6^{14}$. Here the $\mathrm{pH}$ adjustment of wastewater may be performed by the addition of chemical agents ( $\mathrm{NaOH}$ or $\mathrm{KOH})$ and monitored by a $\mathrm{pH}$ sensor which may be complicated and expensive equipment ${ }^{15}$. Now, the airagitated reactor is commonly proposed for the MAP precipitation because of its capability in stripping of $\mathrm{CO}_{2}$, in which the use of air aeration results in a system with an intimate contact between air and makes the $\mathrm{pH}$ solution increasing ${ }^{15,16}$. In terms of process conditions, $\mathrm{pH} 9$ could be selected as optimum value, while few changes in temperature (from $25^{\circ} \mathrm{C}$ to $36^{\circ} \mathrm{C}$ ) may have no influence on chemical precipitation. Furthermore, the chemical reaction stages following the way of the MAP crystallization relate to the supersaturated solution, nucleation (crystal birth), and crystal growth ${ }^{17,18}$. Moreover, the high level of supersaturation yields the small particles with poor settleability, which correspond to the ineffective filtration of the solid-liquid and thereby influencing the crystallized products ${ }^{19}$. Conversely, the transformation rate of orthophosphate may be increased, when the supersaturation levels in the solution are relatively high. But this condition makes a reduction in phosphorus productivity (precipitation on crystal $)^{17}$. Generally, the supersaturated solution can be changed its level by using the modified substance concentrations $^{20,21}$. Moreover, the higher levels of supersaturation could be reached out at low reagent concentration during the MAP crystallization process. It is, therefore, an important to understand the effect of the supersaturation control method applied for the MAP precipitation on phosphorus to be recovered.

The present study presents the supersaturation control strategy for struvite precipitation in the air-agitated reactor with continuous fluid flow using three reagent feed points. In particular, the effects on phosphate recovery efficiency and the characteristic of crystallized products from the MAP crystallization were examined. The phosphorus reclamation efficiency was calculated using data on the phosphorus concentration in the influent and effluent streams, and the saturation index (SI) of the solution under varying retention time and $\mathrm{pH}$. Subsequently, the precipitate's characteristics were examined by X-ray powder diffraction (XRPD) for phase composition and scanning electron micrograph (SEM) for morphological analysis. The results are required to solve the low phosphorus productivity relating to the homogeneous nucleation during the MAP precipitation.

\section{Reactor Design for Use in the Experiment}

\section{EXPERIMENTAL}

The air-agitated column reactor was employed in the study and composed of two zones, the crystallization reaction zone with a cylinder of $50 \mathrm{~cm}$ in height and $10 \mathrm{~cm}$ in diameter (working volume of $0.5 \mathrm{l}$ ); and the 
liquid-solid separation zone on the bottom of the conical reactor which has an outflow diameter of $20 \mathrm{~cm}$ (Figure 1). Feeding was performed through the connections at the top, while sampling of precipitates was discharged out of the bottom of the reactor. The stock powder employed consisted of $0.706 \mathrm{M} \mathrm{NH}_{4} \mathrm{OH}$ (the ammonium source), $1.412 \mathrm{M} \mathrm{H}_{3} \mathrm{PO}_{4}$ (the phosphorus source) and $1.059 \mathrm{MgCl}_{2}$ (the magnesium source) with analytical grade (Merck, Germany).

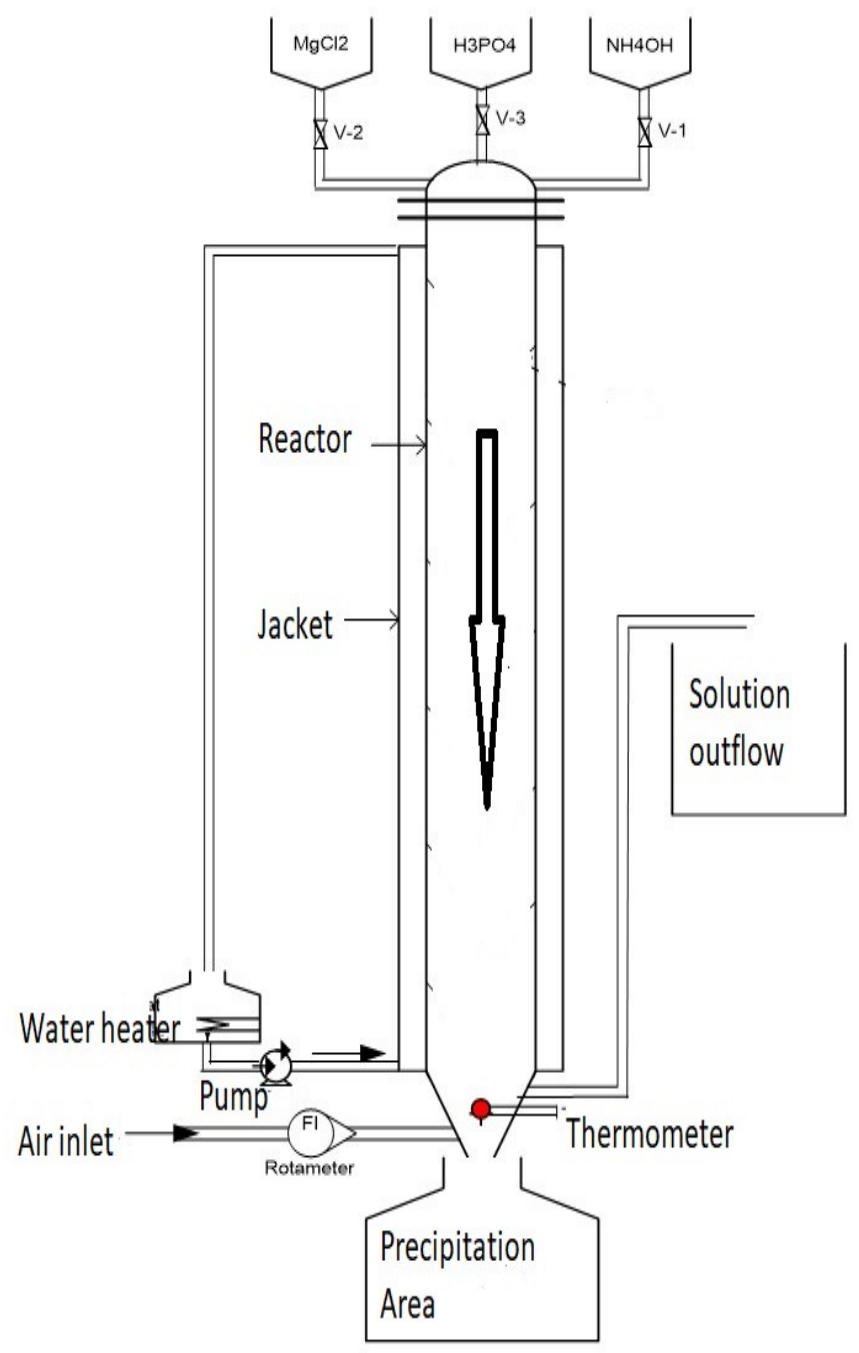

Fig.-1: The reactor design used for phosphorus reclamation as struvite

Further, each stock solution was prepared by dissolving those powders in 500 ml-glass beakers containing distilled water and $0.45 \mathrm{~mm}$ paper filter was employed to separate liquid and the solid particle present in the solution. The resulting solution was kept for a time prior, to be used for experiments. In the MAP crystallization experiments, the three kinds of solutions were filled into each feed port and subsequently flew under gravitation. The air for agitation was pumped from the bottom of the reactor and air aeration flow rate was set at $0.25 \mathrm{ml} / \mathrm{min}$, while each solution flow rates were varied at $16,20,2530$, and 38 $\mathrm{ml} / \mathrm{min}$, respectively. The $\mathrm{pH}$ solution $(8,9$ and 10) was maintained by injection of $1 \mathrm{~N} \mathrm{KOH}$ from the bottom together with air. Each experiment was performed for estimating retention time within the reactor at $13,17,20,25,31$ minutes and temperature of $30^{\circ} \mathrm{C}$. In this way, the $\mathrm{pH}$ was monitored every 5-minute intervals. The solid accumulated in the reaction zone precipitated through an outlet at the bottom of the reactor. In the conical part, the supernatant liquid left from the reactor owing to an overflow system. 
After finishing the process, the precipitates were removed from the precipitation area and then filtered onto the membranes $(0.45 \mu \mathrm{m}$ Millipore HAWP01300, USA), and the resulting solid was subsequently dried at room temperature for 48 hours. The filtrate for remaining $\mathrm{P}_{-} \mathrm{PO}_{4}$ ions was then subjected to analysis using XRF (x-ray fluorescence) instrument (Minipal 4; PAN Analytical). Moreover, the dried product was subsequently analyzed by XRPD Rietveld analysis for mineralogical characterization, while the elemental composition and morphology of the crystals were examined using SEM.

\section{Productivity of Phosphorus Reclamation}

The following equation (1) is given for calculating the phosphorus reclamation efficiency (XA):

$$
\mathrm{XA}=\left(1-\mathrm{C}_{\text {out }} / \mathrm{C}_{\text {in }}\right)
$$

where $\mathrm{C}_{\text {out }}$ is the phosphorus concentration (wt.\%) in the influent and $\mathrm{C}_{\mathrm{in}}$ is the phosphorus concentration in the effluent after sampling by filtering onto $0.45 \mu \mathrm{m}$ membranes.

\section{Supersaturation Estimation of the Solution}

The struvite precipitation in the solution can be described by a reaction as follows:

$$
\mathrm{Mg}^{2+}+\mathrm{NH}_{4}{ }^{+}+\mathrm{HnPO}_{4}{ }^{\mathrm{n}-3}+6 \mathrm{H}_{2} \mathrm{O} \rightarrow \mathrm{MgNH}_{4} \mathrm{PO}_{4} \cdot 6 \mathrm{H}_{2} \mathrm{O}+\mathrm{nH}^{+}
$$

where $\mathrm{n}$ is equal to 0,1 , and 2 ; while this chemical reaction influences the $\mathrm{pH}$ solution.

A thermodynamic chemical equilibrium model of MAP precipitation was calculated with the help of the Visual Minteq program (version 3.0) providing the saturation index (SI) of minerals ${ }^{22}$. The SI can be defined as:

$$
\mathrm{SI}=\log (\mathrm{IAP} / \mathrm{Ksp})
$$

where the ion activity product is presented as IAP, and the solubility product of MAP is indicated by Ksp. When SI $<0$, it means that the solution is unsaturated and thereby precipitation of minerals does not happen. Conversely, the solution is under supersaturation, indicated by SI $>0$. This condition makes spontaneous precipitation taking place in the solution.

Table-1 presents the input data on the chemical composition of the solution for the SI calculation. Furthermore, the Davies activity coefficient was selected for SI calculation in the program. Here, the potential of mineral species was predicted by the program at varying $\mathrm{pH}$ values and temperature of $30{ }^{\circ} \mathrm{C}$.

Table-1: Concentration of a Chemical Element $(\mathrm{g} / \mathrm{l})$ in the Solution used in Experiments

\begin{tabular}{c|c|c|c|c|c}
\hline $\mathrm{Cl}$ & $\mathrm{K}$ & $\mathrm{Mg}$ & $\mathrm{NH}_{4}-\mathrm{N}$ & $\mathrm{PO}_{4}-\mathrm{P}$ & $\mathrm{pH}$ \\
\hline 74.55 & 112 & 25.57 & 14.86 & 134.07 & $8,9,10$ \\
\hline
\end{tabular}

\section{Materials Characterization}

Initially, the dried samples of precipitates were ground for the XRPD measurement. In this way, an aluminum XRPD sample holder was used for holding the powder by pressing it with a glass slide, whereas the XRPD data were collected by X-ray diffractometer (Philips PW 1710) equipped with a Cutube detector. The machine condition for collecting the XRPD data are given in Table- 2 .

Table-2: Measurement Condition of XRPD Collection Data

\begin{tabular}{l|l}
\hline Powder diffractometer & Bragg-Brentano \\
\hline Scan axis & $240 \mathrm{~mm}$ \\
\hline X-ray target & $\mathrm{CuK}_{\alpha}$ \\
\hline Generator voltage and tube current & $40 \mathrm{kV}, 30 \mathrm{~mA}$ \\
\hline Focussing Optik & Normal focus $10 \times 1 \mathrm{~mm}$ \\
\hline Divergence and receiving slits & $0.2117^{\mathrm{O}}$ \\
\hline Soiler slits & $5.3^{\mathrm{O}}$ \\
\hline Resolving slit & $100 \mathrm{~mm}$ \\
\hline
\end{tabular}


RASĀYAN J. Chem.

Vol. 11 | No. 2 |904 - 914 | April - June | 2018

\begin{tabular}{l|l}
\hline Monochromator used & Graphite \\
\hline Detector & Scintillation counter \\
\hline Scan range & $5-90^{\circ} 2 \theta$ (in $0.020^{\circ}$ step size) \\
\hline Time per step & $10 \mathrm{~s}$ \\
\hline
\end{tabular}

Phase identification of crystalline sample was carried out by a computerized search-match (MATCH software) containing PDF (Powder Diffraction File) database of minerals. Moreover, the Rietveld refinement program (Program Fullprof-2k, version 3.30) was employed to verify the identified crystalline phases $^{23}$. The Rietveld refinement was performed using the crystal structure model presented in the AMCSD database (American mineralogist of crystal structure database). The program also refined XRPD peak profiles for the full-width at half-maximum (FWHM) as a function of $\tan (\theta)$ using the u-v-w formula ${ }^{24}$. Determining the weight. \% levels of mineralogical phases were performed using the refined cell parameters. Calculation procedures of the refinement have been discussed elsewhere ${ }^{25}$.

Correspondingly, the dried samples were then observed through SEM for morphological analysis. In this way, the grinding of precipitates was performed by a pestle and mortar providing a powder with sizes < $75 \mu \mathrm{m}$, which was subsequently put onto the Al-sample holder and the powder surface was deposited by carbon prior to conducting SEM analysis.

\section{RESULTS AND DISCUSSION \\ The productivity of the Reactor for Recovering Phosphorus}

The powder, normally fine, is often produced by the crystallization process leading to poor settleability and could be a negative impact on the phosphorus recovery from wastewater ${ }^{17}$. A successful phosphorus recovery from the supernatant solution has been previously demonstrated using the completely airagitated reactor ${ }^{26}$. In this study, the experimental run was directed to examine efficiencies of the phosphorus reclamation from the supersaturated solution in the column reactor, and the impacts of varying $\mathrm{pH}$ and retention time for conversion efficiency (XA).

Figure-2 presents the productivity of the column reactor to recover phosphorus during 40 minutes of retention time. In this case, the retention time was calculated from the volume of solution in the reactor divided by the flow rate of feed solution. At the start of the process operation, the white powder was precipitated, while the slight reduction in $\mathrm{pH}$ could be seen. This condition shows that the homogeneous nucleation happened on the solution at the lower supersaturation as represented by the lower SI value (Fig.-3).

Here a large number of microcrystalline may be produced ${ }^{17}$. At $\mathrm{pH} 8$, the initial phosphorus content in the solution was approximately $42.93 \%$, and the efficiency (presented as $\ln \mathrm{X}_{\mathrm{A}}$ ) decreased sharply in the 16minutes operation. With the increasing retention time of the system, the efficiency was continually reduced. After a 38-minute operation, the efficiency was reached $99.66 \%$ and then it remained stable by the average of 4.2 throughout the operational period. The results showed that the struvite crystallization succeeds to recover phosphorus from the solution. Accordingly, the reactor could improve the phosphorus recovery in the process. Likewise, the phosphate was gradually recovered as crystallized products during the operation at $\mathrm{pH} 9$, while the crystals could be formed on the bottom of the reactor at a lower rate of precipitation.

In contrast, at $\mathrm{pH} 10$, the efficiency of phosphorus recovery could be improved when the retention time increased. Consequently, increases in $\mathrm{pH}$ solution promoted the increasing SI of struvite (Figure 3). In this case, the crystal nucleation may dominate the crystal growth of struvite, ultimately resulting in smaller crystals ${ }^{26}$. Moreover, in this reactor technology with three intake points, by varying the retention time and $\mathrm{pH}$ had an influence on the homogeneous nucleation inhibited and thereby phosphorus recovery efficiency would be affected.

\section{Phase Composition and Morphology of the Solid Precipitates}

The phase identification of the corresponding crystal solids obtained from the experiment with 31-minute retention time was performed by the XRPD method, providing that struvite was matched to PDF\#71- 
2089; newberyite $\left(\mathrm{MgHPO}_{4} \cdot 3 \mathrm{H}_{2} \mathrm{O}\right)$ to $\mathrm{PDF} \# 70-2345$ and sylvite $(\mathrm{KCl})$ to PDF\#76-3368. The phase identified was then judged by the XRPD Rietveld refinement method (Fig.-4a).

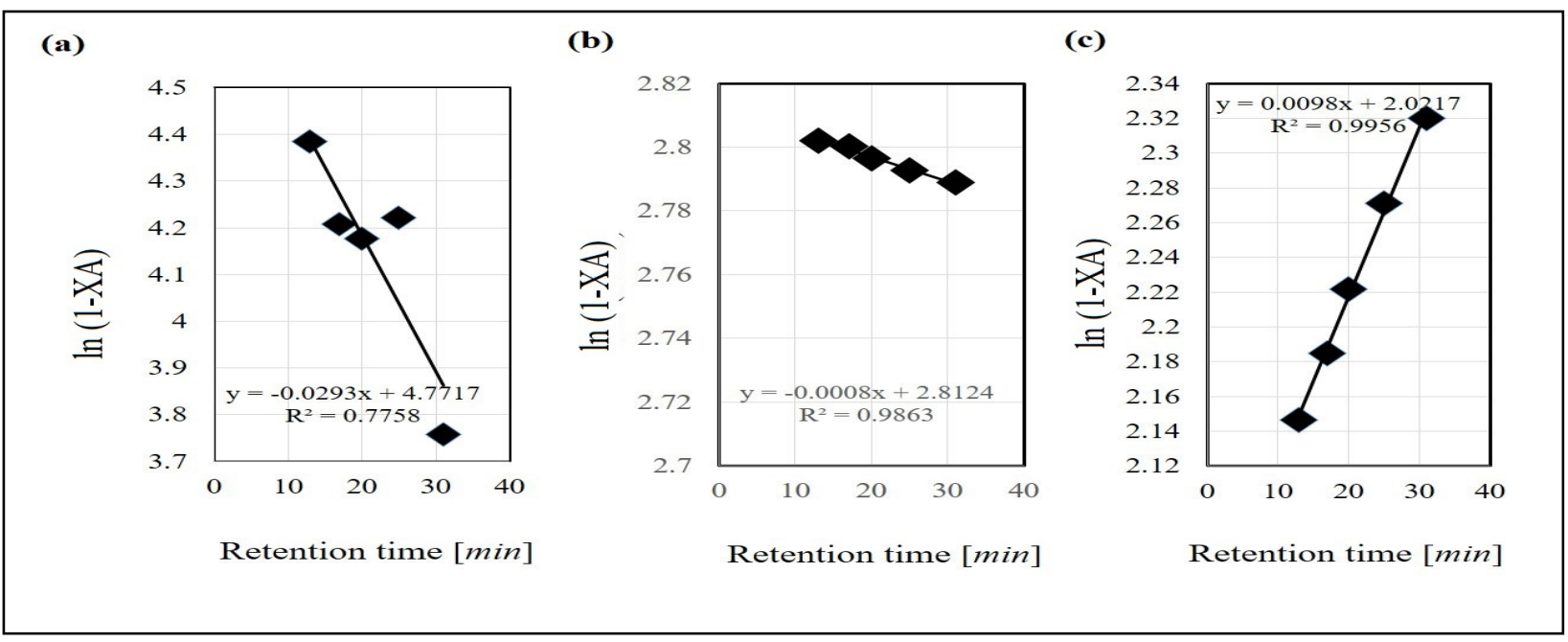

Fig.-2: The variation of process efficiency $\left[\ln \left(\mathrm{X}_{\mathrm{A}}\right)\right]$ versus retention time for $\mathrm{pH}$ solution (a) 8 , (b) 9 and (c) 10 .

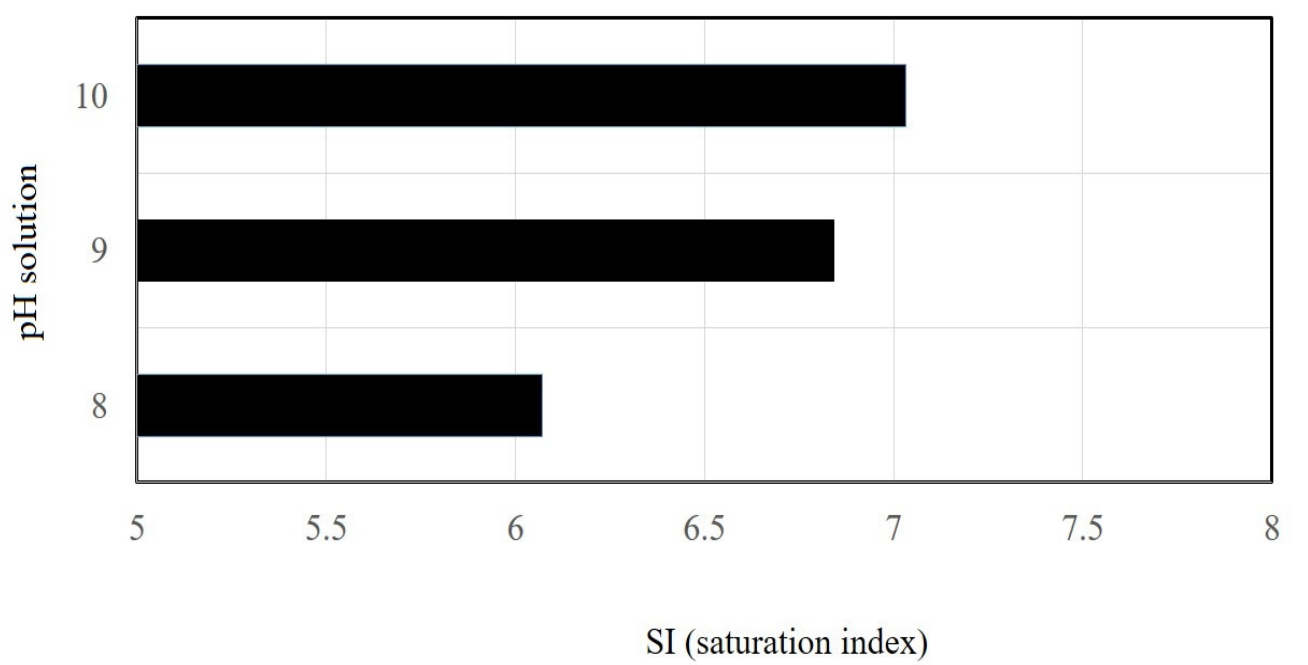

Fig.-3: The calculated saturation index (SI) based on the $\mathrm{pH}$ solution for struvite precipitation

In this method, the overlapping peaks of phases found in the search match or phases incorrectly designated could be judged on the plot showing the difference in the refined and measured intensities of XRPD data ${ }^{27,28}$. Accordingly, the profile fitting of the measured peaks with the refined model provided a correct analysis of the phase composition of the samples. In this present study, the solid precipitates were shown to be crystalline in nature, while a significant glassy phase may be not present in the samples as a broad amorphous peak cannot be seen from the XRPD background.

Upon the XRPD quantitative analysis (Fig.-4b), the crystals are mainly composed of struvite and coprecipitated sylvite $(\mathrm{KCl})$, which had been produced from 13 to 25 minutes of the retention time. In this case, the quantitative XRPD Rietveld analyses confirmed that struvite was precipitated as a major mineral (about 99 wt. \%) with a small percentage of sylvite (<0.5 wt.\%). In contrast, struvite (74.5 wt.\%), newberyite $(25 \mathrm{wt} . \%)$ and sylvite $(<0.5 \mathrm{wt} . \%)$ were the only minerals formed under $\mathrm{pH} 8$ and retention 
time of 31 minutes. Moreover, morphological features of the microcrystalline resulted from the MAP crystallization were examined by SEM and given in Fig.-5.

(a)

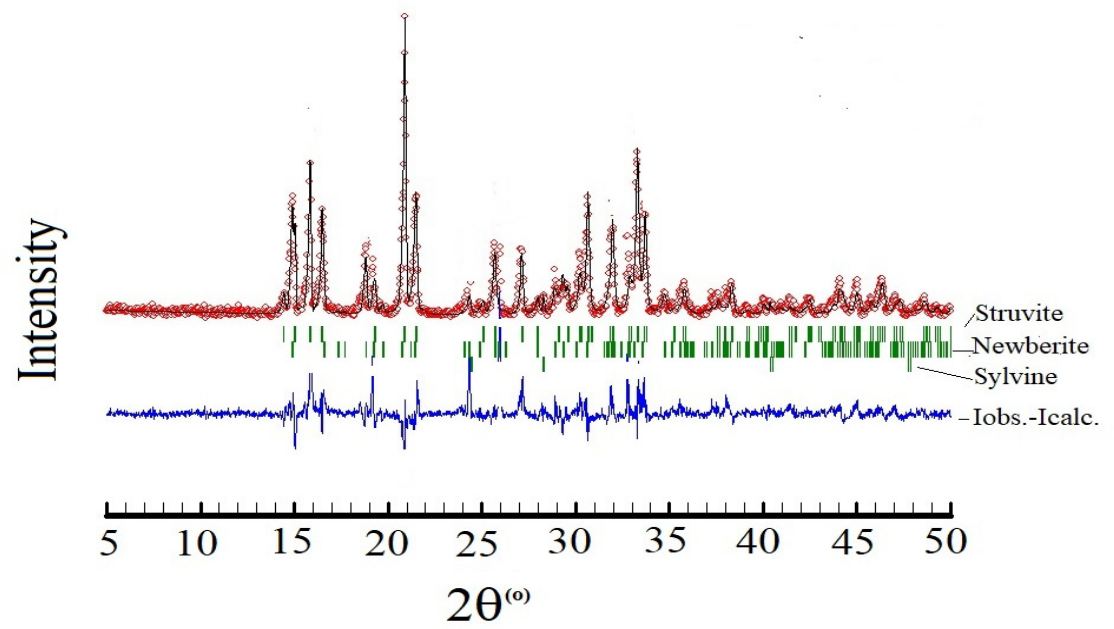

Fig.-4: (a) XRPD Rietveld plot of precipitates obtained after 31-minutes of retention time in the air-agitated column reactor.

(b)

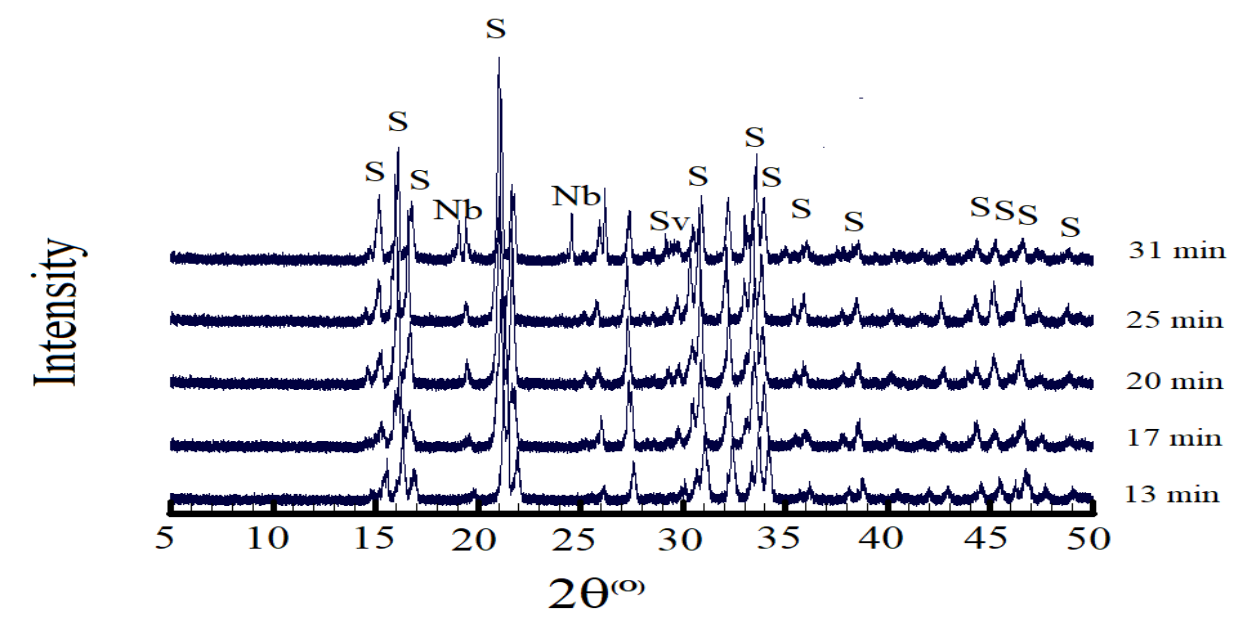

Fig.-4: (b) XRPD diffractogram of precipitates with various retention time at $\mathrm{pH} 8$.

Notes: $\mathrm{Nb}, \mathrm{S}$, and $\mathrm{Sv}$ denote newberyite, struvite and sylvine respectively.

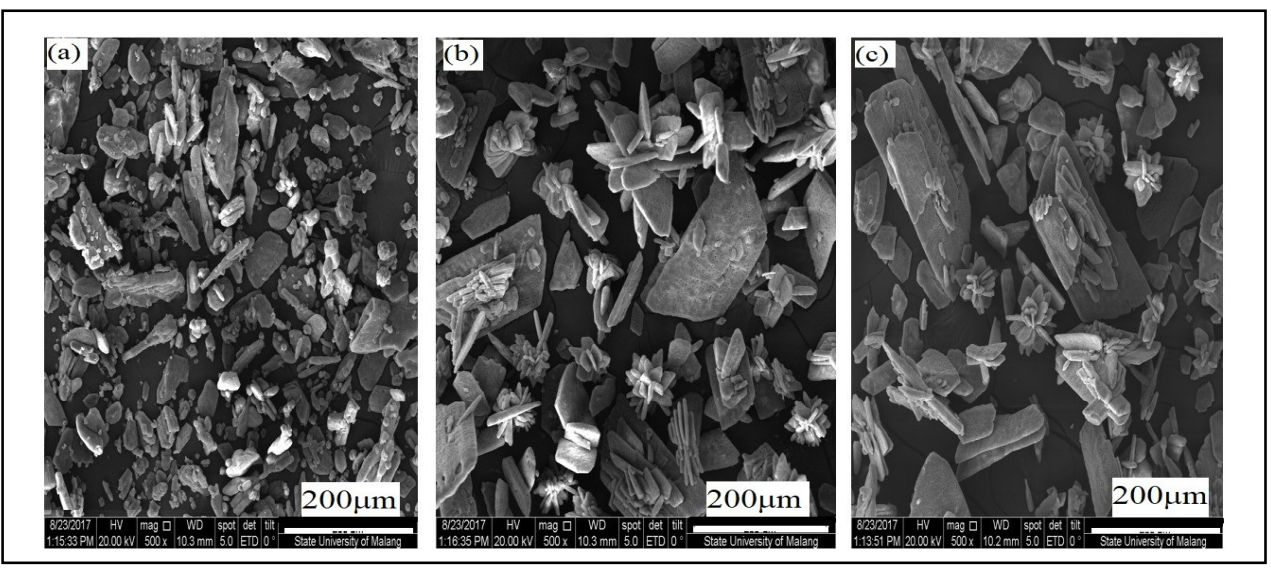

Fig.-5: SEM micrographs of microcrystalline produced at $\mathrm{pH} 8$ in the air-agitated column reactor after (a) 31 minutes; (b) 25 minutes; (c) 21 minutes of retention time. 
The precipitated crystals were agglomerated, indicating the presence of struvite with small-sized crystals (about $100 \mu \mathrm{m}$ ), which was precipitated as a prismatic shape after 31 minutes of the retention time in the air-agitated crystallization reactor. Comparison of these micrographs shows that the MAP formation occurring in the short retention time ( 25 or 21 minutes) resulted in a larger number of the crystal (Figures $5 b-c)$. The micrograph of microcrystalline exhibited an untied particle which was obtained from the different retention time, thereby the MAP precipitation induced for phosphorus reclamation may improve the morphological and homogeneous particles in size.

(a)

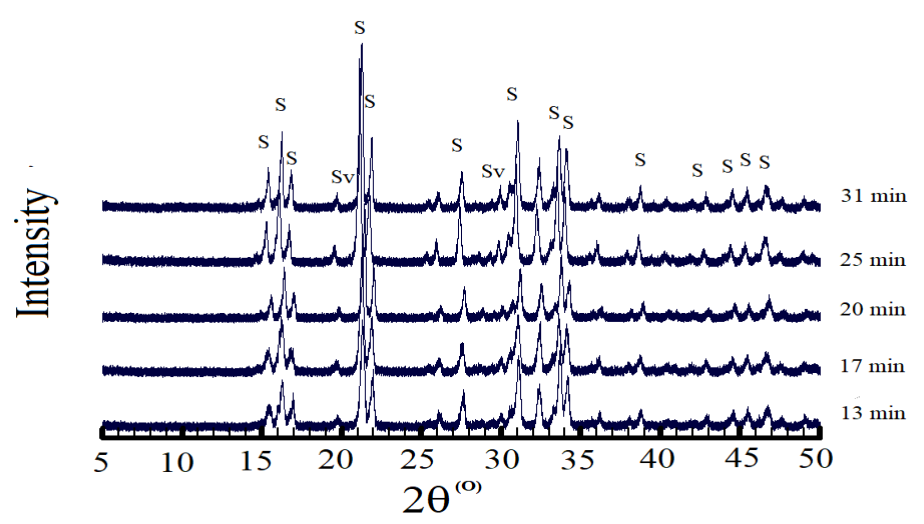

(b)

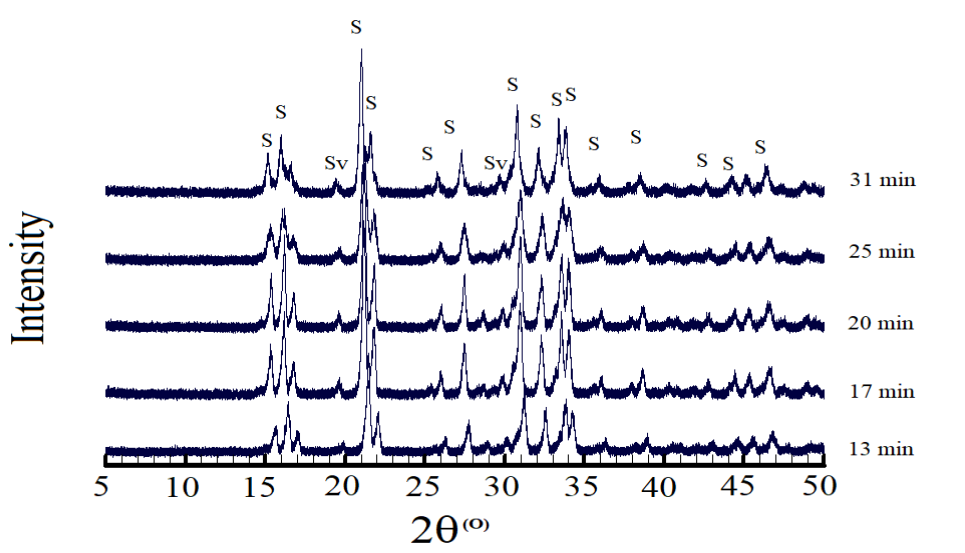

Fig.-6: X-ray diffractogram of precipitates obtained from various retention time and $\mathrm{pH}$ solution of (a) 9; (b) 10.

Notes: $\mathrm{S}$ and $\mathrm{Sv}$ denote struvite and sylvine respectively.

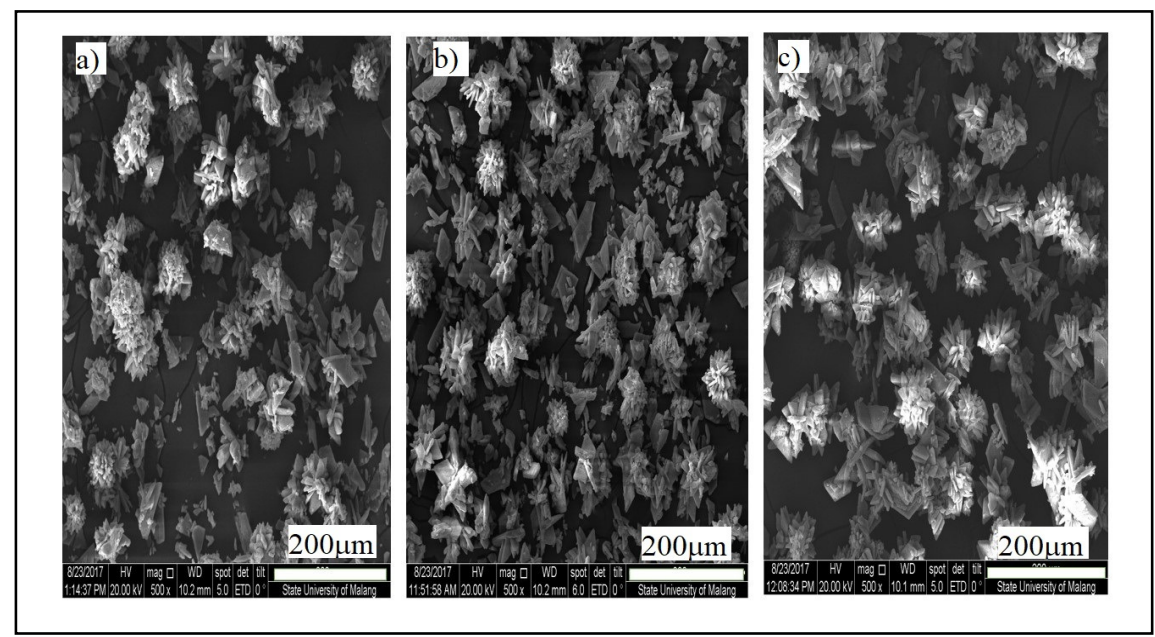

Fig.-7: SEM micrographs of microcrystalline produced at $\mathrm{pH}$ of 9; (a) 31 minutes; (b) 25 minutes; (c) 21 minutes of retention time. 
The further induced MAP crystallization at various $\mathrm{pH}$ solutions resulted in struvite precipitation and less amount of sylvite. XRPD patterns of precipitating solid are given in Figures $6 \mathrm{a}$ and $6 \mathrm{~b}$. In this case, the mineralogical phase composition of the precipitates did not change because MAP ions (i.e., magnesium, ammonium and phosphate) were under chemical equilibrium. According to the XRPD quantitative analysis, struvite was still major phases precipitated out the solution with various retention time at $\mathrm{pH}$ of 9 and 10.

Further, SEM micrograph of struvite obtained after 31, 25, 20-minutes of retention time for phosphorus recovery at $\mathrm{pH}$ of 9 and 10 show the fineness distribution of the struvite particles (Figures 7 and 8). The morphology of struvite with different particle size was obviously marked. Particles that were coprecipitated from the solution in this process condition may form agglomerates on the surface of struvite crystal. The best morphology of struvite with a homogeneous distribution of particle size could be grown at $\mathrm{pH} 10$ and 31-minutes of retention time. Accordingly, increasing in $\mathrm{pH}$ solution may have contributed to the homogeneous distribution of particle size and morphology of struvite.

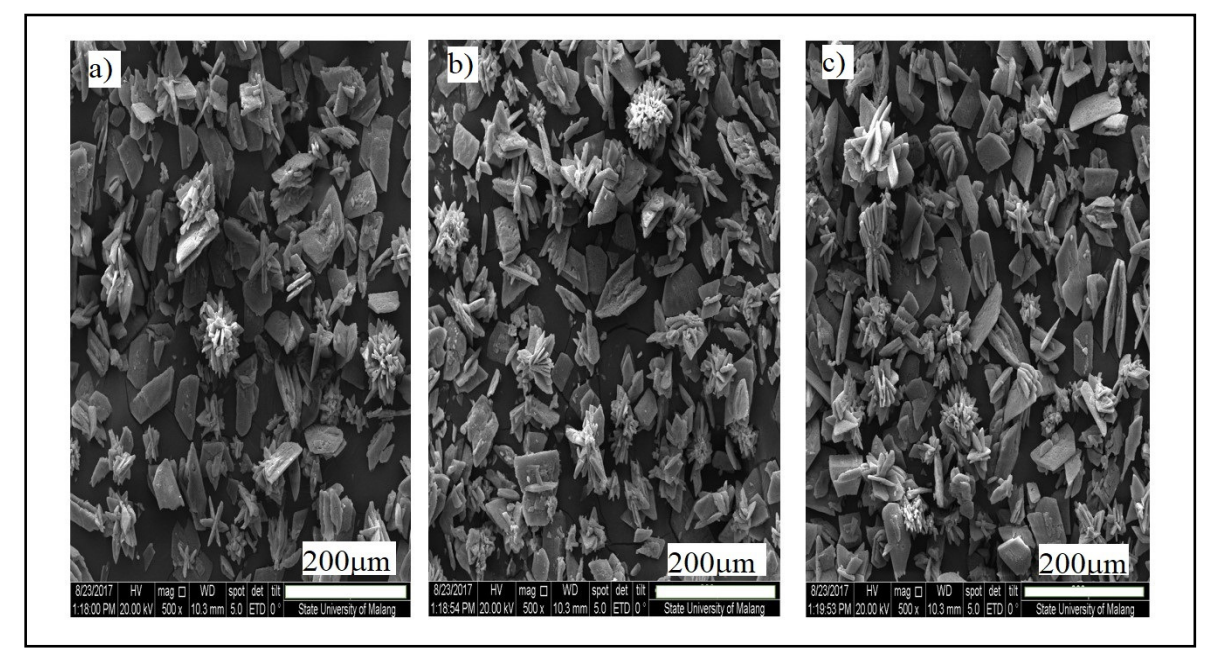

Fig.-8: SEM micrographs of microcrystalline produced at $\mathrm{pH}$ of 10 in the air-agitated column reactor after (a) 31 minutes; (b) 25 minutes; (c) 21 minutes of retention time.

\section{Engineering Significance of the Designed Reactor}

The air-agitated column reactor was designed to accommodate the field application of waste treatment. It has been demonstrated in the study that the phosphorus recovery in the system is technically viable. Nevertheless, the chemical cost of using $\mathrm{Mg}^{2+}$ and $\mathrm{KOH}$ adjustment in the wastewater treatment may be very high ${ }^{29}$. Moreover, a compounding of a fluidized-bed and air agitated reactors has been adopted in the present study. It has been demonstrated that the air aeration promoted with increasing of the $\mathrm{pH}$ solution $^{15}$. The air-aeration could make water and air in close contact, whereas dissolved gases (such as carbon dioxide) could be removed, thereby increasing $\mathrm{pH}$ according to following reaction ${ }^{29}$ :

$$
\mathrm{CO}_{3}^{-2}+\mathrm{NH}_{4}^{+} \rightarrow \mathrm{HCO}_{3}^{-} \rightarrow \mathrm{CO}_{2}(\mathrm{~g})+\mathrm{OH}^{-}
$$

The use of the air aeration for increasing $\mathrm{pH}$ make lower operating cost compared to a chemical cost of additives $(\mathrm{KOH} \text { or } \mathrm{NaOH})^{15}$. However, the increasing $\mathrm{pH}$ with air aeration was not very effective compared to using those chemical additives, observed during the study. Therefore $\mathrm{KOH}$ was still injected into the reactor in combination with using air aeration.

Further, the molar ratios of $\mathrm{Mg}: \mathrm{PO}_{4}$ in the supernatant of wastewater was reported to have a significant effect on the struvite precipitation ${ }^{5}$. However, the chemical cost of the $\mathrm{Mg}^{2+}$ additive incurred in this technology may be lower than the cost of using other waste treatment technology ${ }^{30,31,32}$. Correspondingly, this reactor system is promising to be developed as an industrial reactor, because it is easy to operate with 
a lower running cost. The only energy cost is required for operating the pumps and the aerator. Other costs may be needed for cleaning and maintaining the running reactor ${ }^{33}$. Furthermore, the use of a low cost for chemical additive makes the system be economically feasible. A continuous-flow fluidized bed crystallizer was reported to require about $26 \%$ of the operational costs for the chemical additives and $17.4 \%$ of the running cost for energy ${ }^{33}$. Therefore, this reactor design technology may be adapted to yield the optimum struvite, which is a sound strategy to recover nutrients from effluent and to improve nutrient management for fertilizer.

\section{CONCLUSION}

After the retention time operation of the reactor with various $\mathrm{pH}$ solutions $(8,9$ and 10$)$, the phosphorus reclamation efficiency was obtained as the average of $93.83 \%$, which was slightly reduced by $1.4 \%$ compared with that at the initial $\mathrm{pH}$ 8. The results of XRPD analysis confirm that struvite was a major phase, except for newberyite resulted from crystallization at $\mathrm{pH} 8$ and 31-minutes of the retention time. There was also co-precipitated sylvite found in the struvite crystal. Obviously, the phosphorus uptake as struvite could be demonstrated using the reactor. SEM micrographs showed that struvite morphology with a great quantity of finely distributed prismatic crystal. Nonetheless, further study on controlling the supersaturated solution should be performed by air aeration with varying flow rates.

\section{ACKNOWLEDGMENT}

The authors wish to express our gratitude to Universitas Pembangunan National, "Veteran" Surabaya, Indonesia, which supported in this Ph.D. research project. The review's comments and suggestion are also acknowledged.

\section{REFERENCES}

1. H. Dai, X. Lu, Y. Peng, Z. Yang, H. Zhsssu, Environ. Sci. Pollut. Res., 24, 5791(2017), DOI: 10.1007/s11356-016-8236-2

2. Y.H. Song, P.G. Weidler, U. Berg, B.G. Weidler, R. Nueesch, D. Dietfried, Chemosphere., 63, 236 (2006), DOI: 10.1016/j.chemosphere.2005.08.021

3. U. Berg, D. Donnert, P.G. Weidler, E. Kaschka, G. Knoll, R. Nüesch, Water Sci. Technol., 53, 131(2006), DOI: 10.2166/wst.2006.084

4. H. Zou, W. Yan, Bioresour. Technol., 211, 87(2016), DOI: 10.1016/j.biortech.2016.03.073

5. K. S. Le Corre, E. Valsami-Jones, P. Hobbs, S.A. Parsons, Environ. Sci. Technol., 39, 433(2009), DOI:10.1080/10643380701640573

6. A.L. Forrest, P.K. Fattah, D.S. Mavinic, F.A. Koch, J. Environ. Eng., 134, 395(2008), DOI: 10.1061/(ASCE)0733-9372(2008)134:5(395)

7. W. G. Harris, A. C. Wilkie, X. Cao, R. Sirengo, Bioresour. Technol., 99, 3036(2008), DOI: 10.1016/j.biortech.2007.06.065

8. K.S. Le Corre, E.V. Jones, P. Hobbs, B. Jefferson, S.A. Parsons, Water Res., 41, 2449(2007), DOI: 10.1016/j.watres.2007.03.002.

9. L. E. de-Bashan, Y. Bashan, Water Res., 38, 4222(2004), DOI: 10.1016/j.watres.2004.07.014

10. M. Latifian, J. Liu, B. Mattiasson, Environ. Technol., 33, 2691(2012), DOI: 10.1080/09593330.2012.676073

11. N.Hutnik, A. Kozik, A. Mazienczuk, K. Piotrowski, B. Wierzbowska, A. Matynia, Water Res., 47, 3635(2013), DOI: 10.1016/j.watres.2013.04.026

12. T.P. Mokone, R.P. Van Hille, A.E. Lewis, Water Res., 46, 2088(2012), DOI: 10.1016/j.watres.2012.01.027

13. H. Huang, J. Liu, L. Ding, J. Clean. Prod., 102, 437(2015), DOI:10.1016/j.jclepro.2015.04.117

14. Y. Jaffer, T.A. Clark, P. Pearce, S.A. Parsons, Water Res., 36, 1834(2002), DOI: 10.1016/S00431354(01)00391-8

15. K. Suzuki, Y. Tanaka, T. Osada, M. Waki, Water Res., 36, 2991(2002), DOI:10.1016/S00431354(01)00536-X

16. B.U. Kim, W.H. Lee, H.J. Lee, J.M. Rim, Water Sci. Technol., 49, 215(2004)

THE EFFECT OF SUPERSATURATION CONTROL 
RASĀYAN J. Chem.

Vol. 11 | No. 2 |904 - 914 | April - June | 2018

17. N. Karapinar, E. Hoffmann, H.H. Hahn, Water Res., 40, 1210(2006), DOI: 10.1016/j.watres.2005.12.041

18. C.W. Yang, T.S. Lui, Acta Biomater., 5, 2728(2009), DOI: 10.1016/j.actbio.2009.03.014

19. V.T. Lewis Costodes, A.E. Lewis, Chem. Eng. Sci., 61, 1377(2006), DOI: 10.1016/j.ces.2005.08.038

20. J.W. Mullin, Crystallization. Butterworth-Heinemann, Oxford, (2001)

21. D.S. Perwitasari, S. Muryanto, J. Jamari, A.P. Bayuseno. JECE., 6, 37-43(2018), DOI: 10.1016/j.jece.2017.11.052

22. USEPA, A geochemical assessment model for environmental systems: Version 3.0 user manual.U.S. EPA/600/3-91/021. Washington, DC, (1991)

23. J. Rodriguez-Carvajal, Program Fullprof 2k, version 3.30, Laboratoire Leon Brillouin, France, June(2005)

24. G. Caglioti, A. Paoletti, F.P. Ricci, Nuclear Instrument., 35, 223(1958)

25. P.-Y. Mahieux, J.-E. Cyr, M. Aubert, M. Coutand, B. Husson, Waste Manage., 30, 378(2010), DOI: 10.1016/j.wasman.2009.10.023

26. K. Suzuki, Y. Tanaka, K. Kuroda, D. Hanajima, Y. Fukumoto, T. Yasuda, T, M. Waki, Bioresour. Technol., 98, 1573(2007), DOI: 10.1016/j.biortech.2006.06.008

27. H.M. Rietveld, J. Appl. Crystallogr., 2, 45(1969), DOI: 10.1107/S0021889869006510

28. E. Prince, Mathematical aspects of Rietveld refinement. The Rietveld Method. Edited by Young, R.A. International Union of Crystallography, Oxford, New York, 43-54(1993)

29. I. Çelen, Water Sci. Techno., 60, 2271(2009), DOI: 10.2166/wst.2009.683

30. S.K. Sharma, A. Chaudharyb, R.V. Singh, Rasayan J. Chem., 1, 68(2008)

31. N. K. Swamy, P. Singh, I.P.Sarethy, Rasayan J. Chem., 4, 452(2011)

32. B. Anup Nikhil, S. Ramesh, S. Dhanasekar, J. S. Sudarsan, Rasayan J. Chem., 10, 1114(2017), DOI:10.7324/RJC.2017.1041729

33. P.W. Westerman, K.E. Bowers, K.D. Zering, Transactions of the American Society of Agricultural and Biological Engineers., 26, 153(2010)

[RJC-3007/2018] 